\title{
Malignant Peripheral Nerve Sheath Tumors State of the Science: Leveraging Clinical and Biological Insights into Effective Therapies
}

\author{
AeRang Kim, ${ }^{1}$ Douglas R. Stewart, ${ }^{2}$ Karlyne M. Reilly, ${ }^{3}$ David Viskochil, ${ }^{4}$ \\ Markku M. Miettinen, ${ }^{5}$ and Brigitte C. Widemann ${ }^{6}$ \\ ${ }^{1}$ Center for Cancer and Blood Disorders, Children's National Health System, 111 Michigan Ave NW, Washington, DC 20010, USA \\ ${ }^{2}$ Clinical Genetics Branch, Division of Cancer Epidemiology and Genetics, National Cancer Institute, 9609 Medical Center Drive, \\ Room 6E450, Bethesda, MD 20892, USA \\ ${ }^{3}$ Rare Tumors Initiative, OD, CCR, National Cancer Institute, 37 Convent Drive, Bethesda, MD 20814, USA \\ ${ }^{4}$ University of Utah, 295 Chipeta Way, Salt Lake City, UT 84108, USA \\ ${ }^{5}$ Center for Cancer Research, National Cancer Institute, 10 Center Drive, Room 2S235C, Building 10, Bethesda, MD 20892, USA \\ ${ }^{6}$ National Cancer Institute, Pediatric Oncology Branch, 10 Center Drive, Room 1-3742, Building 10, Bethesda, MD 20892, USA
}

Correspondence should be addressed to AeRang Kim; aekim@childrensnational.org

Received 6 February 2017; Accepted 3 April 2017; Published 16 May 2017

Academic Editor: Alexander Lazar

Copyright (c) 2017 AeRang Kim et al. This is an open access article distributed under the Creative Commons Attribution License, which permits unrestricted use, distribution, and reproduction in any medium, provided the original work is properly cited.

Malignant peripheral nerve sheath tumor (MPNST) is the leading cause of mortality in patients with neurofibromatosis type 1. In 2002, an MPNST consensus statement reviewed the current knowledge and provided guidance for the diagnosis and management of MPNST. Although the improvement in clinical outcome has not changed, substantial progress has been made in understanding the natural history and biology of MPNST through imaging and genomic advances since 2002. Genetically engineered mouse models that develop MPNST spontaneously have greatly facilitated preclinical evaluation of novel drugs for translation into clinical trials led by consortia efforts. Continued work in identifying alterations that contribute to the transformation, progression, and metastasis of MPNST coupled with longitudinal follow-up, biobanking, and data sharing is needed to develop prognostic biomarkers and effective prevention and therapeutic strategies for MPNST.

\section{Introduction}

Neurofibromatosis type 1 (NF1) is an autosomal dominant, pan-ethnic disorder with an incidence of 1:3000 [1]. NF1 is characterized by diverse, progressive cutaneous, neurologic, skeletal, and neoplastic manifestations with limited therapeutic options. The leading cause of death in NF1 patients is the malignant peripheral nerve sheath tumor (MPNST), a highly aggressive soft tissue sarcoma [2]. Half of all MPNST develop in individuals with NF1, with a 5-year survival of about $20 \%$ to $50 \%$, and the outcome is especially dismal in those with unresectable or metastatic disease [2, 3]. Most (65-88\%) NF1 MPNST arise from plexiform neurofibromas (PN) [4], benign peripheral nerve sheath tumors that are a hallmark of NF1. The only known definitive therapy for MPNST is surgical resection with wide negative margins $[4,5]$, which is often not feasible or indicated due to location, size, and metastases $[6,7]$.

A 2002 MPNST consensus statement reviewed current knowledge, provided guidance for the diagnosis and management of MPNST, and identified research priorities [8]. While little progress has been made in the development of more effective therapies since then, there have been substantial advances in understanding MPNST natural history, biology, and preclinical modeling, and preclinical and clinical trial consortia have been established (Table 1). In this review, we update progress since 2002 in the (1) natural history of peripheral nerve sheath tumors, (2) pathogenesis of MPNST, (3) development of preclinical models, and (4) management and clinical trials for MPNST. 
TABLE 1: Summary of progress in preclinical, clinical, and therapeutic MPNST research and clinical management since the 2002 international consensus conference.

\begin{tabular}{|c|c|c|}
\hline Characteristic & 2002 & 2016 \\
\hline $\begin{array}{l}\text { Natural history of } \mathrm{PN} \\
\text { growth }\end{array}$ & $\begin{array}{l}\text { (i) Unknown } \\
\text { (ii) May be erratic }\end{array}$ & $\begin{array}{l}\text { (i) Well characterized } \\
\text { (ii) Identification of distinct nodular lesions (DNL) } \\
\text { with different growth pattern }\end{array}$ \\
\hline Imaging & $\begin{array}{l}\text { (i) Role of FDG-PET unclear } \\
\text { (ii) FLT PET should be considered }\end{array}$ & $\begin{array}{l}\text { (i) FDG-PET has clear role } \\
\text { (ii) FLT-PET under evaluation }\end{array}$ \\
\hline Pathology & $\begin{array}{l}\text { (i) ANF do not fit in category } \\
\text { (ii) Locally aggressive } \\
\text { (iii) Do not metastasize }\end{array}$ & (i) Identification of ANF as MPNST precursor \\
\hline Risk for transformation $\uparrow$ & (i) Nodular PN, large central PN, NF neuropathy & (i) Distinct nodular, FDG-avid lesions \\
\hline Pathogenesis & $\begin{array}{l}\text { (i) NF1 microdeletion } \\
\text { (ii) } p 27, p 53, p 16\end{array}$ & $\begin{array}{l}\text { (i) } C D K N 2 A / B \\
\text { (ii) } S U Z 12, E E D\end{array}$ \\
\hline Mouse models & (i) Briefly mentioned & (i) Preclinical trials consortium using GEMM \\
\hline $\begin{array}{l}\text { Chemotherapy targeted } \\
\text { therapy }\end{array}$ & (i) Very few, if any, MPNST-specific data & $\begin{array}{l}\text { (i) Prospective trial of chemotherapy completed } \\
\text { (ii) MPNST-specific targeted trials ongoing } \\
\text { (iii) SARC and NF clinical trials consortium }\end{array}$ \\
\hline Access to tissue & (i) Importance of tissue banking & (i) CTF NF biobank \\
\hline Data collection & (i) International database recommended & (i) No international database established \\
\hline
\end{tabular}

ANF: atypical neurofibroma; DNL: distinct nodular lesion; FDG-PET: fluorodeoxyglucose positron emission tomography; FLT-PET: fluorothymidine positron emission tomography; GEMM: genetically engineered mouse model; PN: plexiform neurofibroma; SARC: Sarcoma Alliance for Research through Collaboration (research and advocacy group); CTF: Children's Tumor Foundation.

\section{Natural History of Peripheral Nerve Sheath Tumors}

PN, a cardinal feature of NF1, are identified in up to $50 \%$ of individuals with NF1 [9]. They are a major source of morbidity [10], causing disfigurement, impairment of nerve function, pain, and in some cases transform to MPNST (Figure 1) [2, 3]. Magnetic resonance imaging (MRI) and fluorodeoxyglucose(FDG-) positron emission tomography (PET) are utilized in the diagnosis of malignant transformation with features to aid in distinguishing MPNST from PN [11-14]. Since 2002, the use of whole-body and targeted longitudinal MRI with volumetric analysis has permitted the sensitive and reproducible characterization of PN growth [15-19]. Most PN growth occurs in children, and substantial PN volume increase is infrequent in adults. This is in contrast to distinct nodular lesions (DNL) which have been identified using longitudinal whole-body MRI and display different imaging and growth characteristics [20, 21]. On Short T1 Inversion Recovery (STIR) MRI, these lesions are nodular, $\geq 3 \mathrm{~cm}$ in longest diameter, and well demarcated and lack the "central dot" sign characteristic of PN. MRI imaging for MPNST demonstrate irregularly shaped, ill-defined margins, intratumoral lobulation, and inhomogeneous contrast enhancement [12]. DNL emerge after early childhood, their growth rate is not agerelated, and they are frequently higher than that of surrounding or adjacent PN. In contrast to typical PN, most DNL are FDG-avid on FDG-PET [21, 22] more like MPNST [13]. Biopsy and excision of some radiographically detected DNL reveal histologically atypical neurofibromas (ANF). ANF share some features of low-grade MPNST and recognition of transformation of ANF to MPNST suggests that ANF are premalignant lesions of MPNST rather than variants of PN [23].
ANF have increased variable cellularity and have cells with enlarged, hyperchromatic nuclei and more pronounced fascicular growth $[23,24]$. Taken together, these findings suggest that DNL have a distinct underlying biology compared to PN [20]. Genomic findings of CDKN2A/B loss in ANF and MPNST (but not PN) further support the hypothesis that ANF are precursor lesions for MPNST [22, 23, 25]. In a retrospective analysis of 76 ANF diagnosed in 63 patients with NF1, the majority $(n=57)$ were resected and have not recurred [22]. However, four ANF transformed into high grade MPNST. Sixteen patients had a history or developed MPNST in a different location, and patients with ANF may be at greater risk of developing MPNST [22]. Limited correlation of clinical outcome in surgical excision of ANF suggests that these lesions may not require aggressive surgery as MPNST. In a retrospective review of 23 patients who underwent surgical resection of a plexiform neurofibroma pathologically diagnosed as either low-grade MPNST or ANF had diseasespecific survival of $100 \%$ with a median follow-up of 47 months despite $78 \%$ (18/23) of patients having microscopically positive margins [26]. No patients developed pulmonary metastasis. Further study is warranted, but focal surgical resection of premalignant ANF may play an important role in the prevention of MPNST.

\section{Pathology of MPNST}

Sarcoma arising from the peripheral nerve sheath is readily diagnosed as MPNST if the tumor clearly has nerve elements or arises in the context of NF1. Otherwise, the diagnosis of MPNST is more difficult, with a broad differential diagnosis of other sarcomas, and requires an extensive clinicopathologic assessment of immunohistochemical (IHC) markers, 
(a)

(b)
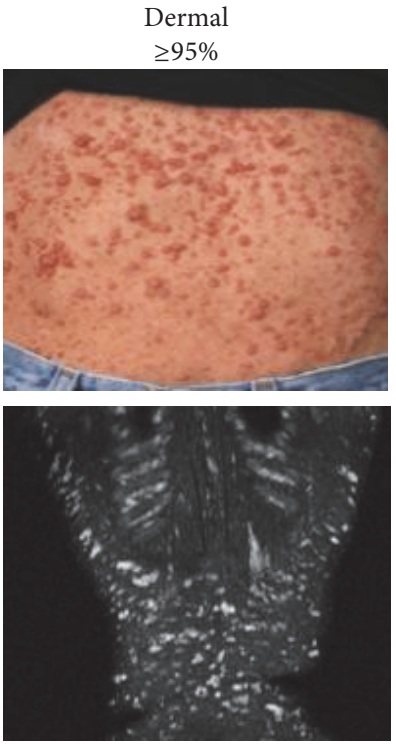

(c)

(d)

$$
\begin{array}{|l}
\text { Appearance, pruritus } \\
\hline \text { Loss of } N F 1
\end{array}
$$

Neurofibroma/nerve sheath tumor
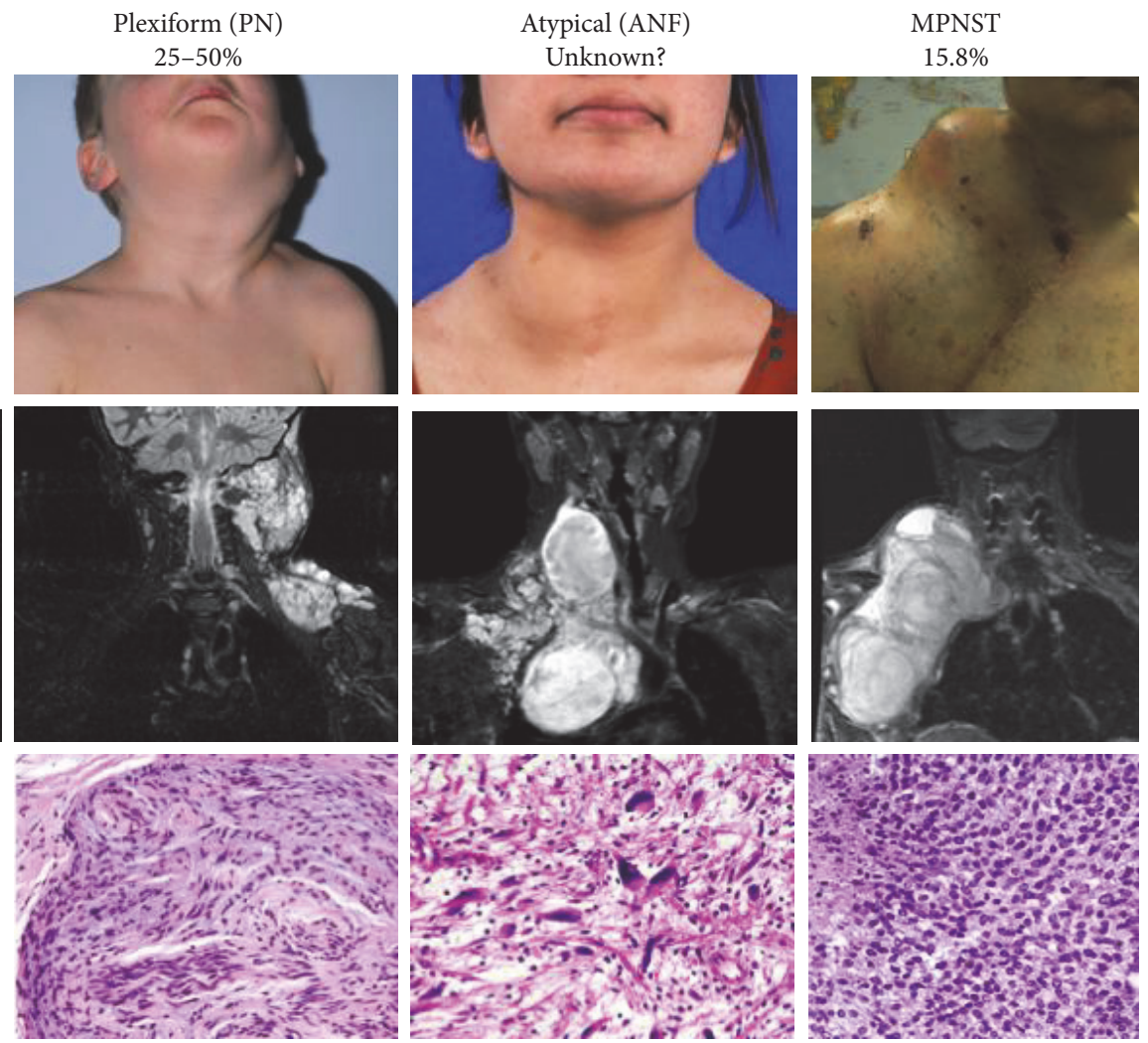

Appearance, pain, function loss, $\rightarrow$ malignant transformation

Figure 1: Pathogenesis of peripheral nerve sheath tumors in NF1. Percentages below each tumor type is the range of lifetime prevalence in individuals with NF1. Representative clinical photograph (a), MRI imaging (b), histology (c), clinical symptomology (d), and genetic features (e) of each tumor type are given. Histologically, plexiform neurofibroma shows mixture of areas of hypercellularity in the absence of other atypical features. Atypical neurofibroma shows atypical nuclei and higher cellularity. In contrast, MPNST are highly cellular with high mitotic activity and areas of necrosis.

tissue ultrastructure, and histologic findings [24,27] to firmly establish a tumor diagnosis. High-grade MPNST are highly cellular with many mitotic figures and areas of necrosis. Lowgrade MPNST are less cellular, have few mitotic figures and no areas of necrosis, and are difficult to distinguish from benign cellular neurofibromas and ANF. Various histologic patterns can coexist within a single specimen, making it imperative to examine as much of the tumor as possible to arrive at an appropriate diagnosis and grade [28]. Small biopsies are usually inadequate for clinical decision-making due to this intratumor heterogeneity.

IHC studies are helpful in distinguishing high-grade MPNST from other sarcomas but are less helpful in distinguishing ANF from low-grade MPNST. Typical staining includes in situ antibody studies on multiple formalin-fixed sections for S100 (calcium-binding motif as Schwann cell marker), Ki-67 (nuclear nonhistone protein marker of cell proliferation), TP53 (tumor suppressor marker for transformation), CD34 (sialomucin glycoprotein as nonspecific marker of endothelium and hematopoietic stem cells), and pl6INK4a (cell-cycle inhibitory protein marker that is inactivated in MPNST). A standardized set of IHC markers has not been routinely applied to peripheral nerve sheath tumors across clinical pathology laboratories. Although they may be useful in characterizing MPNST [29], the pattern of IHC staining has not led to stratification of patients for personalized management of their tumor. Use of genetic markers in these tumors is emerging as another modality to more fully characterize peripheral nerve sheath tumors for clinical intervention.

\section{Genetics and Genomics of MPNST}

MPNST cells harbor complex rearranged genomes. Accumulated evidence suggests that NF1 loss is necessary but not sufficient for MPNST development. As NF1-associated MPNST progress from NF1-nullizygous $\mathrm{PN}$, they acquire mutations in other driver genes (e.g. TP53 and CDKN2A). NF1 loss is seen 
in a majority of sporadic MPNST, suggesting that NF1 is an important tumor suppressor in all MPNST. Genetic alterations of CDKN2A and TP53 are also observed in sporadic and radiation-associated MPNST [30]. Deletion of CDKN2A disrupts two encoded proteins (p16INK4A and p19ARF) and their associated regulatory cascades. CDKN2A deletions are also observed in ANF [23]. The first study of NF1-associated tumor progression in a single patient from $\mathrm{PN}$ to primary MPNST and MPNST metastasis using whole exome sequencing (WES) of biopsies [31] found biallelic NF1 mutations in all tumor stages, chromosome 17p (TP53) loss in primary MPNST and metastasis, and no CDKN2A deletions or EGFR amplifications. Subsequent cytogenetic and array comparative genomic hybridization $(\mathrm{aCGH})$ studies on MPNST have identified frequent losses on chromosomes 1p, 9p, 11, 12p, $14 \mathrm{q}, 18,22 \mathrm{q}, \mathrm{X}$, and $\mathrm{Y}$, with focal gains on chromosomes 7 , $8 \mathrm{q}$, and $15 \mathrm{q}$ [32]. There are no pathognomonic chromosomal translocations in MPNST. Amplification of genes encoding the epidermal growth factor (EGF) receptor, neuregulin-1 (NRG1) coreceptor erbB2, c-Kit, platelet-derived growth factor- $\alpha$, and c-Met has been reported in MPNST [33].

In 2014, somatic mutations in SUZ12 and EED encoding components of the polycomb repressive complex 2 (PRC2) were reported in NF1-associated and sporadic MPNST [30, $34,35]$. PRC2 is a histone methyltransferase and plays a critical role in marking chromatin for silencing. This finding suggests that transformation to MPNST involves a previously unsuspected epigenetic switch and points to potential epigenetic-based therapeutic strategies. Comprehensive genomic characterization of sporadic, NF1-, and radiationassociated MPNST shows recurrent inactivation of PRC2 from somatic mutation of EED and SUZ12 [30, 35]. The SUZ12 gene encodes a chromatin modifying protein, and its loss enhances colony growth of NF1-deficient (but not NF1 wildtype) glioblastoma cells, suggesting that reduced PRC2 levels might promote tumorigenesis. Furthermore, SUZ12 ablation causes loss of trimethylation at lysine 27 of histone $\mathrm{H} 3$ (H3K27me3) and increased H3K27 acetylation, establishing transcriptional activation marks to recruit bromodomain proteins that are potential drug targets for MPNST [34].

Frequent somatic alterations of CDKN2A and NF1 significantly co-occur with PRC2 alteration. SUZ12 is located near NF1 in 17q11.2 and is involved in both type 1 and type 2 microdeletions at the NF1 locus. Such microdeletions are associated with an increased risk of MPNST [36], leading to a model in which a "third hit" in SUZ12 (the first two hits being the loss of NF1 and one copy of SUZ12 from a 17q11.2 microdeletion) drives transformation to MPNST [30]. PRC2 catalyzes trimethylation of $\mathrm{H} 3 \mathrm{~K} 27$ and multiple studies have found that significant loss of H3K27me3 in MPNST is associated with poor survival; furthermore, such loss is not observed in $\mathrm{PN}$ or ANF [37-39]. H3K27me3 loss or PRC2 mutation may be a useful biomarker to diagnose MPNST [35].

\section{Preclinical Models}

The primary model systems used to study MPNST have been (1) cell lines derived from MPNST patients, (2) xenograft models of patient-derived MPNST cells injected subcutaneously or into the sciatic nerve of immune compromised mice, (3) patient-derived xenografts (PDX) that have not been cultured, and (4) genetically engineered mouse models of sporadic MPNST.

5.1. Cell Culture Models. MPNST tumor lines from human and mouse have been used to elucidate the mechanism of action of neurofibromin [40]; study the role of tyrosine kinase receptors [41-47], growth factors [48-50], p53 [51, 52], microRNAs [30, 53], and sex hormones [54-56] in MPNST biology; and examine the effects of chemotherapy [57-67] and viral therapy [68-71] as potential treatments for MPNST. The most commonly used strains for grafting have been S462, ST8814 , and STS26T. STS26T was isolated from a metastatic lesion and has been shown to form metastases when injected into the tail vein of the mouse [62].

At least $33 \mathrm{NF1}$ or sporadic MPNST lines from primary or metastatic human tumors and mice tumors have been described in the literature to varying degrees (Supplemental Table 1, in Supplementary Material available online at https:// doi.org/10.1155/2017/7429697). Mouse tumor lines have been made by isolating tumors with MPNST histology from $\mathrm{Nf1}^{-/+}: \operatorname{Trp} 53^{-/+}$cis mice (see below).

5.2. Xenograft/Orthograft Models. Over half of the described MPNST tumor lines have been used in grafting experiments to recapitulate the biology of MPNST in mice. The majority of these experiments studied human MPNST cells in immunedeficient mice. Although some cancer cell types are known to grow only on certain immune-deficient backgrounds (e.g., NSG), MPNST cells can engraft in hosts with residual immune function. MPNST cell lines that have been reported to engraft in mice and the type of mouse background used are listed in Supplemental Table 1. Xenograft models have been primarily used to test candidate therapeutics for MPNST.

5.3. Patient-Derived Xenograft (PDX) Models. Culture and xenograft models have been the mainstay of testing novel therapeutics for MPNST over the past 20 years. There is controversy regarding how well these models predict response in patients. This has led to the development of additional models that seek to better emulate the tumor microenvironment. Tumor cells passaged in culture adapt to the lack of extracellular matrix and culture-specific exogenous growth factors. PDX models are created by implanting patient tumor tissue directly into immune-deficient mice, so that the tumor cells grow directly within an in vivo environment. Very few of these models have been published. It is not clear how many have been maintained by passaging for use by other investigators. Bhola et al. [55] isolated tumor tissue from a male young adult NF1 patient and implanted small pieces subcutaneously into male NOD/SCID mice. The explants retained the histological and IHC characteristics of the parental tumor over more than 15 passages [72, 73].

5.4. Genetically Engineered Mouse Models (GEMMs). GEMMs develop MPNST spontaneously, permitting the coevolution 
TABLE 2: Genetically engineered mouse models (GEMMs).

\begin{tabular}{|c|c|c|c|c|c|c|c|}
\hline Tumor suppressors mutated & Method of mutation & $\begin{array}{c}\text { Oncogenes } \\
\text { overexpressed }\end{array}$ & $\begin{array}{c}\text { Promoter } \\
\text { overexpressed }\end{array}$ & Grade & $\begin{array}{l}\text { Latency } \\
\text { (months) }\end{array}$ & $\begin{array}{c}\text { Penetrance } \\
(\%)\end{array}$ & REF \\
\hline $\mathrm{Nfl}^{-/+} ; \mathrm{Ink} 4 \mathrm{a}^{-/-} ; \mathrm{Arf}^{-/-}$ & Germline $^{1}$ & & & High & 6.5 & 26 & [79] \\
\hline $\mathrm{Nff}^{\text {flox/flox }} ;$ Pten $^{\text {flox/flox }}$ & Cre $\left(\mathrm{Dhh}^{+}\right.$cells $)$ & & & High & 0.5 & 92 & {$[80]$} \\
\hline $\mathrm{Nf1}^{\text {flox/flox }} ; \operatorname{Pten}^{\text {flox/+ }}$ & Cre (Dhh ${ }^{+}$cells $)$ & & & Low & 5.7 & 42 & [80] \\
\hline $\mathrm{Nfl}^{\text {flox/+}} ;$ Pten $^{\text {flox/flox }}$ & Cre $\left(\mathrm{Dhh}^{+}\right.$cells $)$ & & & Low & 5.8 & 82 & {$[80]$} \\
\hline $\mathrm{Nff}^{\text {flox/flox }}+\mathrm{Nf1}$; p53shRNA & Cre $\left(\text { Periostin }{ }^{+} \text {cells }\right)^{4}$ & & & Low & 6.1 & 56 & {$[87]$} \\
\hline $\mathrm{Nfl}^{\text {flox/- }}+\mathrm{Nf1} ; \mathrm{p} 53$ shRNA & Cre $\left(\mathrm{GFAP}^{+} \text {cells }\right)^{4}$ & & & Low & 3.0 & 73 & [87] \\
\hline $\mathrm{Nfl}^{\text {flox/flox }} ; \operatorname{Ink} 4 \mathrm{a}^{\text {flox/flox }} ;$ Arf flox/flox & Cre (injection) & & & High & 4.1 & 100 & {$[86]$} \\
\hline $\mathrm{Nf1}^{-/+}: \operatorname{Trp} 53^{-/+}$ & Germline $^{2}$ & & & High & 5 & 81 & {$[77,78]$} \\
\hline $\mathrm{Nf1} 1^{\text {flox/flox }}$ & Cre $\left(\mathrm{Dhh}^{+}\right.$cells $)$ & EGFR & $\mathrm{CNP}$ & High & $\sim 6$ & 33 & {$[81]$} \\
\hline $\operatorname{Trp} 53^{-/+}$ & Germline $^{3}$ & EGFR & $\mathrm{CNP}$ & Low-high & 9.5 & 19 & {$[84]$} \\
\hline Pten ${ }^{\text {flox/+ }}$ & Cre $\left(\mathrm{GFAP}^{+}\right.$cells $)$ & Kras-G12D & lox-STOP-lox ${ }^{5}$ & High & $\sim 6$ & 100 & [82] \\
\hline Pten $^{\text {flox/flox }}$ & Cre $\left(\mathrm{Dhh}^{+}\right.$cells $)$ & EGFR & $\mathrm{CNP}$ & High & $<1$ & 100 & [83] \\
\hline $\operatorname{Trp} 53^{-/+}$ & Germline $^{3}$ & GGF $\beta 3$ & P0 & Low-high & 7.5 & 95 & [57] \\
\hline NA & NA & GGF $\beta 3$ & $\mathrm{P} 0$ & ND & 8.7 & 71 & {$[85]$} \\
\hline
\end{tabular}

${ }^{1}$ Spontaneous loss of NF1; ${ }^{2}$ spontaneous loss of NF1 and $\mathrm{p} 53 ;{ }^{3}$ spontaneous loss of $\mathrm{p} 53 ;{ }^{4}$ injection of shRNA into sciatic nerve; ${ }^{5}$ activation by Cre (GFAP ${ }^{+}$cells). NA: not applicable; ND: not determined.

of microenvironment and tumor. One GEMM $\left(\mathrm{Nfl}^{-/+}\right.$: $\operatorname{Trp} 53^{-/+}$cis mice) is being used for preclinical screening of drugs through the NF Therapeutic Consortium (NFTC) [34, 74-76]. The available GEMMs for MPNST use several approaches to initiate tumorigenesis: (1) spontaneous loss of heterozygosity of tumor suppressor genes, (2) expression of oncogenes by nervous system promoters, (3) Cre-lox system for mutation or conditional activation of genes during nerve development, or (4) adenoviral or lentiviral expression of shRNAs (Table 2). Heterozygous mutation of Nfl alone is not sufficient to drive MPNST tumorigenesis in mice; however, combining Nf1 mutation with other mutations (Trp53, Pten, and $C d k n 2 a)$ gives rise to MPNST. In addition, MPNST GEMMs have been developed without mutation of Nf1, possibly recapitulating sporadic MPNST. The first MPNST GEMM was the $\mathrm{Nfl}^{-/+}: \operatorname{Trp} 53^{-/+}$cis mouse $[77,78]$ with mutated copies of Nf1 and Trp53 in cis on mouse chromosome 11. Spontaneous loss of the wild-type alleles of these genes initiates tumorigenesis. Combining Nfl heterozygosity with loss of $C d k n 2 a$, encoding $\mathrm{p} 16^{\mathrm{INK} 4 \mathrm{~A}}$ and $\mathrm{p} 19^{\mathrm{ARF}}$, gives rise to MPNST with low penetrance [79]. The Cre-lox system has been used in several GEMMs to mutate Nf1, Trp53, Pten, and/or Cdkn2a in cells of the developing nervous system [8083], as well as to activate mutant Kras [82]. Some GEMMs have combined overexpression of the oncogenes Egfr or $G g f b 3$ with tumor suppressor mutation by driving oncogene expression in nervous system cells using CNP or $P_{0}$ promoters, respectively [57, 80, 81, 84, 85]. More recently, MPNSTs have been modeled using injections into adult mouse sciatic nerve. Injection of adenovirus expressing Cre into mice carrying floxed alleles of $\mathrm{Nfl}$ and $\mathrm{Cdkn} 2 \mathrm{a}$ drives high-grade MPNST through localized loss of neurofibromin, $\mathrm{p} 16^{\text {Ink4a }}$, and $\mathrm{p} 19^{\mathrm{Arf}}$ in the nerve [86]. Low-grade MPNSTs form with the injection of shRNA for both Nfl and Trp53 into mice that are either mutant for $\mathrm{Nfl}$ in all Periostin ${ }^{+}$cells or mutant for $\mathrm{Nfl}$ in $\mathrm{GFAP}^{+}$cells on a heterozygous mutant $\mathrm{Nfl}$ background [87]. Injection GEMMs have the advantage that tumorigenesis occurs in a more synchronized and spatially controlled manner; however, they require surgery for every mouse to expose the sciatic nerve for injection. GEMMs show different latencies for MPNST depending on the genes involved (Cdkn2a, Pten, Trp53, and Egfr) and the method used to mutate genes (shRNA knockdown versus genomic mutation through the Cre-lox system) (Table 2).

\section{Clinical Trials Advances}

Current treatment of MPNST is similar to treatment of soft tissue sarcomas as a whole and relies primarily on local control measures [5]. The only known definitive therapy for MPNST is surgical resection with wide negative margins, which may not be feasible due to variables such as tumor size, location, and/or metastases [7]. The role of adjuvant radiation is not defined; however, it is often recommended for highgrade lesions $>5 \mathrm{~cm}$ in size or with marginal excision $[8$, $88,89]$. For these patients, preoperative radiation should be considered [90]. Although radiation has shown improved local control, no effect on survival has been demonstrated $[91,92]$. The role of chemotherapy is not defined. In a prospective study of chemotherapy (ifosfamide, doxorubicin, and etoposide) in NF1 associated and sporadic MPNST, a lower objective response rate was seen in NF1 patients (18\%) compared with patients with sporadic MPNST patients (44\%), similar to prior studies [93, 94]; however, disease stabilization was achieved in most patients at 4 cycles [95]. The best approach to treatment is by a multidisciplinary team of surgical, medical, and radiation oncologists, radiologists, and pathologists, all with sarcoma expertise. Patients with recurrent, unresectable, or metastatic disease have no known 
TABLE 3: Targeted agents for treatment of MPNST: previous and ongoing clinical trials.

\begin{tabular}{|c|c|c|c|c|c|c|c|}
\hline Drug & Target & Phase & $n$ & Population & Outcome & Results & Ref. \\
\hline Erlotinib & EGFR & II & 24 & $\begin{array}{c}\geq 18 \mathrm{y} \\
\text { Refractory }\end{array}$ & $\begin{array}{c}\text { Response } \\
\text { WHO [101] }\end{array}$ & $\begin{array}{c}19 / 20 \text { pts. } \\
\text { PD at } 2 \text { months } \\
1 \text { SD }\end{array}$ & [96] \\
\hline Sorafenib & $\begin{array}{c}\text { C-Raf } \\
\text { B-Raf VEGFR2 } \\
\text { C-Kit PDGFR }\end{array}$ & II & 12 & $\begin{array}{c}\geq 18 \mathrm{y} \\
\text { Refractory }\end{array}$ & $\begin{array}{c}\text { Response } \\
\text { RECIST [102] }\end{array}$ & $\begin{array}{c}\text { No responses; } \\
\text { median PFS } 1.7 \\
\text { months }\end{array}$ & [97] \\
\hline Imatinib & $\begin{array}{c}\text { C-Kit PDGFR } \\
\text { VEGFR }\end{array}$ & II & 7 & $\begin{array}{c}>10 y \\
\text { Refractory }\end{array}$ & $\begin{array}{c}\text { Response } \\
\text { RECIST [102] }\end{array}$ & $\begin{array}{c}\text { No responses; } \\
1 \mathrm{SD}\end{array}$ & [98] \\
\hline Dasatinib & C-Kit SRC & II & 14 & $\begin{array}{c}\geq 13 \mathrm{y} \\
\text { Refractory }\end{array}$ & $\begin{array}{l}\text { Response } \\
\text { CHOI [103] }\end{array}$ & No response or SD & [99] \\
\hline Alisertib & AURKA & II & 10 & $\begin{array}{c}\geq 18 \mathrm{y} \\
\text { Refractory }\end{array}$ & $\begin{array}{c}\text { Response } \\
\text { RECIST [102] }\end{array}$ & $\begin{array}{l}\text { No response } \\
\text { PFS } 13 \text { weeks }\end{array}$ & {$[100]$} \\
\hline Bevacizumab/RAD001 & Angiogenesis/mTOR & II & - & $\begin{array}{c}\geq 18 \mathrm{y} \\
\text { Refractory }\end{array}$ & $\begin{array}{c}\text { Response } \\
\text { WHO [101] }\end{array}$ & Currently ongoing & - \\
\hline Ganetespib/Sirolimus & $\begin{array}{l}\text { Hsp90 } \\
\text { mTOR }\end{array}$ & $\mathrm{I} / \mathrm{II}$ & - & $\begin{array}{c}\geq 16 y \\
\text { Refractory }\end{array}$ & $\begin{array}{c}\text { Response } \\
\text { WHO [101] }\end{array}$ & Currently ongoing & - \\
\hline
\end{tabular}

curative options and enrollment in clinical trials should be considered.

The EGFR inhibitor erlotinib was the first targeted agent used in a histology-specific phase II trial for MPNST [96], based on the compelling preclinical observation that EGFR amplification was observed in MPNSTs and that Nf1/p53 murine MPNST were stimulated by EGF and inhibited by EGFR inhibitors [33]. Within 22 months, 24 patients were enrolled, but no activity was demonstrated. Subsequent trials of investigational agents (Table 3) have failed to demonstrate efficacy but show that the outcome for unresectable MPNST is poor with a median progression-free survival of less than 2 months and overall survival of less than 5 months [97-100]. These trials demonstrate that single histology trials in this rare disease are feasible and that MPNST progresses rapidly.

Selection, prioritization, and trial design are key challenges in the clinical development of effective therapies for MPNST. While preclinical drug discovery outpaces clinical development, the time and cost to evaluate promising therapies for MPNST are significant and patient numbers are limited. The Children's Tumor Foundation (CTF) and Neurofibromatosis Therapeutic Acceleration Program (NTAP) sponsor the preclinical NF Therapeutic Consortium (NFTC), which supports the conduct of preclinical trials of targeted therapies in GEMM targeting NF1 manifestations (e.g., MPNST and PN) to prioritize the selection of agents for clinical trials. There are no data yet demonstrating MPNST GEMM as valid surrogates for drug activity in humans. Through clinical consortia initiatives such as the Department of Defense (DoD) NF Clinical Trials Consortium and the SARC (Sarcoma Alliance for Research through Collaboration), therapies identified through these models are being translated into clinical trials specific for MPNST. Cooperative group participation allows for rapid accrual for early phase trials in MPNST. Approaches to accelerating testing of agents guided by preclinical rationale, with efficient endpoints, protocol design, and access to drugs, are needed. In turn, these trials can serve as a means to not only validate the best preclinical models, and information gained in the clinic can be used to help develop new therapeutic approaches at the bench.

\section{Future Directions}

Although the outcome for MPNST has not changed significantly since 2002, the more complete understanding of the natural history of peripheral nerve sheath tumors and of the genomic changes during malignant transformation of $\mathrm{PN}$ to ANF and MPNST offers hope for the development of more effective diagnostic, therapeutic, and prevention strategies for MPNST. Whole-body MRI and PET imaging may have utility for risk stratification and for implementation of surveillance and medical/surgical interventions as potential preventative therapies and for monitoring treatment response in large, irregular-shaped tumors. Research priorities should focus on the role of whole-body MRI to screen for PN-related tumor load and on longitudinal imaging to detect lesions concerning malignant transformation, such as DNL. The natural history of ANF needs to be better understood, including its clinical presentation, incidence of malignant transformation of DNL to ANF, and the role for timing and extent (wide versus limited) of surgical excision of these transitional tumors, while resource-intensive, prospective, longitudinal studies of individuals with NF1 and PN with whole-body MRI and other imaging modalities coupled with genomic and immunohistological data and collection of blood samples for potential biomarker development are predicted to have great value in advancing approaches to the diagnosis, treatment, and prevention of MPNST.

Great strides have been made in the development of preclinical models for understanding disease pathogenesis and drug testing in MPNST. Translating and validating preclinical models will require developing validated biomarkers of disease and outcome measures using new technologies that can be incorporated into clinical trials. The search for MPNST biomarkers must have new urgency. Circulating tumor DNA 
is essentially unstudied in MPNST and may offer great promise to screen and detect early cancers, score treatment response, and identify tumor recurrence. The importance of epigenetic mechanisms in MPNST pathogenesis has been underappreciated until the advent of comprehensive genomic studies which have offered clues to future therapies. An international MPNST database with phenotypic, genotypic, and treatment data is needed to share findings and inform next steps for research efforts and treatment strategies [104]. The tumor phenotype data should be comprehensive and include complete characterization of the tumors from clinical pathologists with expertise in sarcoma. To that end, standard and broadly accepted definitions of what constitutes benign cellular neurofibroma, DNL, ANF, low-grade MPNST, and high-grade MPNST need to be established. Molecular data needed for the MPNST database include constitutional DNA, tumor DNA, tumor expression patterns, circulating cell-free DNA, and possibly metabolic activity of the tumor. Treatment and outcome data need to be collated with the genotypephenotype information in the database. Innovative clinical trial designs with efficient endpoints to accelerate testing of new drugs and access to novel agents for testing in combination are also needed.

\section{Conflicts of Interest}

The authors declare that they have no conflicts of interest.

\section{Acknowledgments}

This work has been supported in part by the NCI Center for Cancer Research and Division of Cancer Epidemiology and Genetics intramural research programs.

\section{References}

[1] R. E. Ferner, "Neurofibromatosis 1 and neurofibromatosis 2: a twenty first century perspective," The Lancet Neurology, vol. 6, no. 4, pp. 340-351, 2007.

[2] D. G. R. Evans, M. E. Baser, J. McGaughran, S. Sharif, E. Howard, and A. Moran, "Malignant peripheral nerve sheath tumours in neurofibromatosis," Journal of Medical Genetics, vol. 39, no. 5, pp. 311-314, 2002.

[3] E. Uusitalo, M. Rantanen, R. A. Kallionpää et al., "Distinctive cancer associations in patients with neurofibromatosis type 1," Journal of Clinical Oncology, vol. 34, no. 17, pp. 1978-1986, 2016.

[4] H. Meany, B. C. Widemann, and N. Ratner, "Malignant peripheral nerve sheath tumors: prognostic and diagnostic markers and therapeutic targets," in Neurofibromatosis Type 1, pp. 445467, Springer, Berlin, Germany, 2012.

[5] C. L. Scaife and P. W. T. Pisters, "Combined-modality treatment of localized soft tissue sarcomas of the extremities," Surgical Oncology Clinics of North America, vol. 12, no. 2, pp. 355-368, 2003.

[6] P. W. Pisters, D. H. Leung, J. Woodruff, W. Shi, and M. F. Brennan, "Analysis of prognostic factors in 1,041 patients with localized soft tissue sarcomas of the extremities," Journal of Clinical Oncology, vol. 14, no. 5, pp. 1679-1689, 1996.
[7] G. Gupta, A. Mammis, and A. Maniker, "Malignant peripheral nerve sheath tumors," Neurosurgery Clinics of North America, vol. 19, no. 4, pp. 533-543, 2008.

[8] R. E. Ferner and D. H. Gutmann, "International consensus statement on malignant peripheral nerve sheath tumors in neurofibromatosis," Cancer Research, vol. 62, no. 5, pp. 15731577, 2002.

[9] V.-F. Mautner, F. A. Asuagbor, E. Dombi et al., "Assessment of benign tumor burden by whole-body MRI in patients with neurofibromatosis 1," Neuro-Oncology, vol. 10, no. 4, pp. 593598, 2008.

[10] A. Kim, A. Gillespie, E. Dombi et al., "Characteristics of children enrolled in treatment trials for NF1-related plexiform neurofibromas," Neurology, vol. 73, no. 16, pp. 1273-1279, 2009.

[11] J. Wasa, Y. Nishida, S. Tsukushi et al., "MRI features in the differentiation of malignant peripheral nerve sheath tumors and neurofibromas," American Journal of Roentgenology, vol. 194, no. 6, pp. 1568-1574, 2010.

[12] A. Matsumine, K. Kusuzaki, T. Nakamura et al., "Differentiation between neurofibromas and malignant peripheral nerve sheath tumors in neurofibromatosis 1 evaluated by MRI," Journal of Cancer Research and Clinical Oncology, vol. 135, no. 7, pp. 891900, 2009.

[13] R. E. Ferner, J. F. Golding, M. Smith et al., " $\left[{ }^{18} F\right] 2$-fluoro-2deoxy-D-glucose positron emission tomography (FDG PET) as a diagnostic tool for neurofibromatosis 1 (NF1) associated malignant peripheral nerve sheath tumours (MPNSTs): a longterm clinical study," Annals of Oncology, vol. 19, no. 2, pp. 390394, 2008.

[14] S. M. Broski, G. B. Johnson, B. M. Howe et al., "Evaluation of ${ }^{18}$ F-FDG PET and MRI in differentiating benign and malignant peripheral nerve sheath tumors," Skeletal Radiology, vol. 45, no. 8, pp. 1097-1105, 2016.

[15] E. Dombi, S. L. Ardern-Holmes, D. Babovic-Vuksanovic et al., "Recommendations for imaging tumor response in neurofibromatosis clinical trials," Neurology, vol. 81, no. 21, supplement 1, pp. S33-S40, 2013.

[16] E. Dombi, J. Solomon, A. J. Gillespie et al., "NF1 plexiform neurofibroma growth rate by volumetric MRI: relationship to age and body weight," Neurology, vol. 68, no. 9, pp. 643-647, 2007.

[17] D. H. Gutmann, J. O. Blakeley, B. R. Korf, and R. J. Packer, "Optimizing biologically targeted clinical trials for neurofibromatosis," Expert Opinion on Investigational Drugs, vol. 22, no. 4, pp. 443-462, 2013

[18] J. Solomon, K. Warren, E. Dombi, N. Patronas, and B. Widemann, "Automated detection and volume measurement of plexiform neurofibromas in neurofibromatosis 1 using magnetic resonance imaging," Computerized Medical Imaging and Graphics, vol. 28, no. 5, pp. 257-265, 2004.

[19] R. Nguyen, E. Dombi, B. C. Widemann et al., "Growth dynamics of plexiform neurofibromas: a retrospective cohort study of 201 patients with neurofibromatosis 1," Orphanet Journal of Rare Diseases, vol. 7, article 75, 2012.

[20] S. Akshintala, S. Bhaumik, A. Venkatesan et al., "Identification of lesions concerning for transformation to malignant peripheral nerve sheath tumors (MPNST) in Neurofibromatosis 1 (NF1)," in Radiological Society of North America, 2014.

[21] H. Meany, E. Dombi, J. Reynolds et al., "18-fluorodeoxyglucosepositron emission tomography (FDG-PET) evaluation of nodular lesions in patients with neurofibromatosis type 1 and plexiform neurofibromas (PN) or malignant peripheral nerve sheath 
tumors (MPNST)," Pediatric Blood and Cancer, vol. 60, no. 1, pp. 59-64, 2013.

[22] C. Higham, E. Legius, N. Ullrich et al., Atypical Neurofibromas in NF1: Clinical, Imaging and Pathology Characteristics, Children's Tumor Foundation, Austin, Tex, USA, 2016.

[23] E. Beert, H. Brems, B. Daniëls et al., "Atypical neurofibromas in neurofibromatosis type 1 are premalignant tumors," Genes Chromosomes and Cancer, vol. 50, no. 12, pp. 1021-1032, 2011.

[24] F. J. Rodriguez, A. L. Folpe, C. Giannini, and A. Perry, "Pathology of peripheral nerve sheath tumors: diagnostic overview and update on selected diagnostic problems," Acta Neuropathologica, vol. 123, no. 3, pp. 295-319, 2012.

[25] B. Widemann, S. Bhaumik, S. Akshintala et al., "Identification of lesions concenring for malignant peripheral nerve sheath tumors in NF1," in Proceedings of the CTOS Members Business Meeting, Salt Lake City, Utah, USA, 2015.

[26] N. M. Bernthal, A. Putnam, K. B. Jones, D. Viskochil, and R. L. Randall, "The effect of surgical margins on outcomes for low grade MPNSTs and atypical neurofibroma," Journal of Surgical Oncology, vol. 110, no. 7, pp. 813-816, 2014.

[27] C. D. M. Fletcher, K. K. Unni, and F. Mertens, WHO Classification of Tumours of Soft Tissue and Bone, IARC, Lyons, France, 4th edition, 2013.

[28] B. W. Scheithauer, J. M. Woodruff, and R. A. Erlandson, Tumors of the Peripheral Nervous System, Atlas of Tumor Pathology Third Series, Armed Forces Institute of Pathology, Washington, DC, USA, 1999.

[29] M. Pekmezci, D. E. Reuss, A. C. Hirbe et al., "Morphologic and immunohistochemical features of malignant peripheral nerve sheath tumors and cellular schwannomas," Modern Pathology, vol. 28, no. 2, pp. 187-200, 2015.

[30] M. Zhang, Y. Wang, S. Jones et al., "Somatic mutations of SUZ12 in malignant peripheral nerve sheath tumors," Nature Genetics, vol. 46, no. 11, pp. 1170-1172, 2014.

[31] A. C. Hirbe, S. Dahiya, C. A. Miller et al., "Whole exome sequencing reveals the order of genetic changes during malignant transformation and metastasis in a single patient with NF1-plexiform neurofibroma," Clinical Cancer Research, vol. 21, no. 18, pp. 4201-4211, 2015.

[32] S. L. Carroll, "The challenge of cancer genomics in rare nervous system neoplasms: malignant peripheral nerve sheath tumors as a paradigm for cross-species comparative oncogenomics," American Journal of Pathology, vol. 186, no. 3, pp. 464-477, 2016.

[33] H. Li, S. Velasco-Miguel, W. C. Vass, L. F. Parada, and J. E. DeClue, "Epidermal growth factor receptor signaling pathways are associated with tumorigenesis in the Nf1:p53 mouse tumor model," Cancer Research, vol. 62, no. 15, pp. 4507-4513, 2002.

[34] T. De Raedt, E. Beert, E. Pasmant et al., "PRC2 loss amplifies Ras-driven transcription and confers sensitivity to BRD4-based therapies," Nature, vol. 514, no. 7521, pp. 247-251, 2014.

[35] W. Lee, S. Teckie, T. Wiesner et al., "PRC2 is recurrently inactivated through EED or SUZ12 loss in malignant peripheral nerve sheath tumors," Nature Genetics, vol. 46, no. 11, pp. 1227-1232, 2014.

[36] T. De Raedt, H. Brems, P. Wolkenstein et al., "Elevated risk for MPNST in NF1 microdeletion patients," American Journal of Human Genetics, vol. 72, no. 5, pp. 1288-1292, 2003.

[37] A. H. G. Cleven, G. A. Al Sannaa, I. Briaire-de Bruijn et al., "Loss of H3K27 tri-methylation is a diagnostic marker for malignant peripheral nerve sheath tumors and an indicator for an inferior survival," Modern Pathology, vol. 29, no. 6, pp. 582-590, 2016.
[38] C. N. Prieto-Granada, T. Wiesner, J. L. Messina, A. A. Jungbluth, P. Chi, and C. R. Antonescu, "Loss of H3K27me3 expression is a highly sensitive marker for sporadic and radiation-induced MPNST,' The American Journal of Surgical Pathology, vol. 40, no. 4, pp. 479-489, 2016.

[39] M. Röhrich, C. Koelsche, D. Schrimpf et al., "Methylation-based classification of benign and malignant peripheral nerve sheath tumors," Acta Neuropathologica, vol. 131, no. 6, pp. 877-887, 2016.

[40] J. E. DeClue, A. G. Papageorge, J. A. Fletcher et al., "Abnormal regulation of mammalian p21ras contributes to malignant tumor growth in von Recklinghausen (type 1) neurofibromatosis," Cell, vol. 69, no. 2, pp. 265-273, 1992.

[41] J. J. Ryan, K. A. Klein, T. J. Neuberger et al., "Role for the stem cell factor/KIT complex in schwann cell neoplasia and mast cell proliferation associated with neurofibromatosis," Journal of Neuroscience Research, vol. 37, no. 3, pp. 415-432, 1994.

[42] A. Badache, N. Muja, and G. H. De Vries, "Expression of Kit in neurofibromin-deficient human Schwann cells: role in Schwann cell hyperplasia associated with type 1 neurofibromatosis," Oncogene, vol. 17, no. 6, pp. 795-800, 1998.

[43] J. E. DeClue, S. Heffelfinger, G. Benvenuto et al., "Epidermal growth factor receptor expression in neurofibromatosis type 1related tumors and NF1 animal models," The Journal of Clinical Investigation, vol. 105, no. 9, pp. 1233-1241, 2000.

[44] I. Dang and G. H. DeVries, "Schwann cell lines derived from malignant peripheral nerve sheath tumors respond abnormally to platelet-derived growth factor-BB," Journal of Neuroscience Research, vol. 79, no. 3, pp. 318-328, 2005.

[45] N. Holtkamp, A. F. Okuducu, J. Mucha et al., "Mutation and expression of PDGFRA and KIT in malignant peripheral nerve sheath tumors, and its implications for imatinib sensitivity," Carcinogenesis, vol. 27, no. 3, pp. 664-671, 2006.

[46] M. Hakozaki, H. Hojo, M. Sato et al., "Establishment and characterization of a novel human malignant peripheral nerve sheath tumor cell line, FMS-1, that overexpresses epidermal growth factor receptor and cyclooxygenase-2," Virchows Archiv, vol. 455, no. 6, pp. 517-526, 2009.

[47] K. E. Torres, Q.-S. Zhu, K. Bill et al., "Activated MET is a molecular prognosticator and potential therapeutic target for malignant peripheral nerve sheath tumors," Clinical Cancer Research, vol. 17, no. 12, pp. 3943-3955, 2011.

[48] J. M. Eckert, S. J. Byer, B. J. Clodfelder-Miller, and S. L. Carroll, "Neuregulin-1 $\beta$ and neuregulin- $1 \alpha$ differentially affect the migration and invasion of malignant peripheral nerve sheath tumor cells," GLIA, vol. 57, no. 14, pp. 1501-1520, 2009.

[49] C. Friedrich, N. Holtkamp, J. Cinatl Jr. et al., "Overexpression of Midkine in malignant peripheral nerve sheath tumor cells inhibits apoptosis and increases angiogenic potency," International Journal of Oncology, vol. 27, no. 5, pp. 1433-1440, 2005.

[50] M. Demestre, M. Y. Terzi, V. Mautner, P. Vajkoczy, A. Kurtz, and A. L. Piña, "Effects of pigment epithelium derived factor (PEDF) on malignant peripheral nerve sheath tumours (MPNSTs)," Journal of Neuro-Oncology, vol. 115, no. 3, pp. 391-399, 2013.

[51] H. Sonobe, T. Takeuchi, M. Furihata et al., "A new human malignant peripheral nerve sheath tumour-cell line, HS-sch-2, harbouring p53 point mutation," International Journal of Oncology, vol. 17, no. 2, pp. 347-352, 2000.

[52] N. Holtkamp, I. Atallah, A.-F. Okuducu et al., "MMP-13 and p53 in the progression of malignant peripheral nerve sheath tumors," Neoplasia, vol. 9, no. 8, pp. 671-677, 2007. 
[53] M. Gong, J. Ma, M. Li, M. Zhou, J. M. Hock, and X. Yu, "MicroRNA-204 critically regulates carcinogenesis in malignant peripheral nerve sheath tumors," Neuro-Oncology, vol. 14, no. 8, pp. 1007-1017, 2012.

[54] G. Q. Perrin, H. Li, L. Fishbein et al., "An orthotopic xenograft model of intraneural NF1 MPNST suggests a potential association between steroid hormones and tumor cell proliferation," Laboratory Investigation, vol. 87, no. 11, pp. 1092-1102, 2007.

[55] P. Bhola, S. Banerjee, J. Mukherjee et al., "Preclinical in vivo evaluation of rapamycin in human malignant peripheral nerve sheath explant xenograft," International Journal of Cancer, vol. 126, no. 2, pp. 563-571, 2010.

[56] S. J. Byer, J. M. Eckert, N. M. Brossier et al., "Tamoxifen inhibits malignant peripheral nerve sheath tumor growth in an estrogen receptor-independent manner," Neuro-Oncology, vol. 13, no. 1, pp. 28-41, 2011.

[57] S. N. Brosius, A. N. Turk, S. J. Byer et al., "Neuregulin-1 overexpression and Trp53 haploinsufficiency cooperatively promote de novo malignant peripheral nerve sheath tumor pathogenesis," Acta Neuropathologica, vol. 127, no. 4, pp. 573-591, 2014.

[58] S. Imaizumi, T. Motoyama, A. Ogose, T. Hotta, and H. E. Takahashi, "Characterization and chemosensitivity of two human malignant peripheral nerve sheath tumour cell lines derived from a patient with neurofibromatosis type 1," Virchows Archiv, vol. 433, no. 5, pp. 435-441, 1998.

[59] Y. Hirokawa, H. Nakajima, C. O. Hanemann et al., "Signal therapy of NF1-deficient tumor xenograft in mice by the anti-PAK1 drug FK228," Cancer Biology and Therapy, vol. 4, no. 4, pp. 379381, 2005.

[60] B. Barkan, S. Starinsky, E. Friedman, R. Stein, and Y. Kloog, “The Ras inhibitor farnesylthiosalicylic acid as a potential therapy for neurofibromatosis type 1," Clinical Cancer Research, vol. 12, no. 18, pp. 5533-5542, 2006.

[61] G. Johansson, Y. Y. Mahller, M. H. Collins et al., "Effective in vivo targeting of the mammalian target of rapamycin pathway in malignant peripheral nerve sheath tumors," Molecular Cancer Therapeutics, vol. 7, no. 5, pp. 1237-1245, 2008.

[62] M. P. Ghadimi, E. D. Young, R. Belousov et al., "Survivin is a viable target for the treatment of malignant peripheral nerve sheath tumors," Clinical Cancer Research, vol. 18, no. 9, pp. 25452557, 2012.

[63] W. Wang, W. Lin, B. Hong et al., "Effect of triptolide on malignant peripheral nerve sheath tumours in vitro and in vivo," Journal of International Medical Research, vol. 40, no. 6, pp. 2284-2294, 2012.

[64] J. Ohishi, M. Aoki, K. Nabeshima et al., "Imatinib mesylate inhibits cell growth of malignant peripheral nerve sheath tumors in vitro and in vivo through suppression of PDGFR- $\beta$," BMC Cancer, vol. 13, article 224, 2013.

[65] P. P. Patwardhan, O. Surriga, M. J. Beckman et al., "Sustained inhibition of receptor tyrosine kinases and macrophage depletion by PLX3397 and rapamycin as a potential new approach for the treatment of MPNSTs," Clinical Cancer Research, vol. 20, no. 12, pp. 3146-3158, 2014.

[66] G. Lopez, K. L. J. Bill, H. K. Bid et al., "HDAC8, A potential therapeutic target for the treatment of malignant peripheral nerve sheath tumors (MPNST)," PLoS ONE, vol. 10, no. 7, Article ID e0133302, 2015.

[67] P. Zhang, X. Yang, X. Ma et al., "Antitumor effects of pharmacological EZH2 inhibition on malignant peripheral nerve sheath tumor through the miR-30a and KPNB1 pathway," Molecular Cancer, vol. 14, no. 1, article 55, 2015.
[68] D. R. Deyle, D. Z. Escobar, K.-W. Peng, and D. Babovic-Vuksanovic, "Oncolytic measles virus as a novel therapy for malignant peripheral nerve sheath tumors," Gene, vol. 565, no. 1, pp. 140145, 2015.

[69] A. R. Maldonado, C. Klanke, A. G. Jeßgga et al., "Molecular engineering and validation of an oncolytic herpes simplex virus type 1 transcriptionally targeted to midkine-positive tumors," Journal of Gene Medicine, vol. 12, no. 7, pp. 613-623, 2010.

[70] Y. Y. Mahller, S. S. Vaikunth, M. C. Ripberger et al., "Tissue inhibitor of metalloproteinase-3 via oncolytic herpesvirus inhibits tumor growth and vascular progenitors," Cancer Research, vol. 68, no. 4, pp. 1170-1179, 2008.

[71] T.-C. Liu, T. Zhang, H. Fukuhara et al., "Dominant-negative fibroblast growth factor receptor expression enhances antitumoral potency of oncolytic herpes simplex virus in neural tumors," Clinical Cancer Research, vol. 12, no. 22, pp. 6791-6799, 2006.

[72] Y. Takamiya, R. M. Friedlander, H. Brem, A. Malick, and R. L. Martuza, "Inhibition of angiogenesis and growth of human nerve-sheath tumors by AGM- 1470," Journal of Neurosurgery, vol. 78, no. 3, pp. 470-476, 1993.

[73] J. Castellsagué, B. Gel, J. Fernández-Rodríguez et al., "Comprehensive establishment and characterization of orthoxenograft mouse models of malignant peripheral nerve sheath tumors for personalized medicine," EMBO Molecular Medicine, vol. 7, no. 5, pp. 608-627, 2015.

[74] T. De Raedt, Z. Walton, J. L. Yecies et al., "Exploiting cancer cell vulnerabilities to develop a combination therapy for ras-driven tumors," Cancer Cell, vol. 20, no. 3, pp. 400-413, 2011.

[75] R. Lock, R. Ingraham, O. Maertens et al., "Cotargeting MNK and MEK kinases induces the regression of NF1-mutant cancers," Journal of Clinical Investigation, vol. 126, no. 6, pp. 21812190, 2016.

[76] C. F. Malone, J. A. Fromm, O. Maertens, T. DeRaedt, R. Ingraham, and K. Cichowski, "Defining key signaling nodes and therapeutic biomarkers in NF1-mutant cancers," Cancer Discovery, vol. 4, no. 9, pp. 1062-1073, 2014.

[77] K. Cichowski, T. S. Shih, E. Schmitt et al., "Mouse models of tumor development in neurofibromatosis type 1," Science, vol. 286, no. 5447, pp. 2172-2176, 1999.

[78] K. S. Vogel, L. J. Klesse, S. Velasco-Miguel, K. Meyers, E. J. Rushing, and L. F. Parada, "Mouse tumor model for neurofibromatosis type 1," Science, vol. 286, no. 5447, pp. 2176-2179, 1999.

[79] N. M. Joseph, J. T. Mosher, J. Buchstaller et al., "The loss of Nf1 transiently promotes self-renewal but not tumorigenesis by neural crest stem cells," Cancer Cell, vol. 13, no. 2, pp. 129-140, 2008.

[80] V. W. Keng, E. P. Rahrmann, A. L. Watson et al., "PTEN and NF1 inactivation in Schwann cells produces a severe phenotype in the peripheral nervous system that promotes the development and malignant progression of peripheral nerve sheath tumors," Cancer Research, vol. 72, no. 13, pp. 3405-3413, 2012.

[81] J. Wu, D. M. Patmore, E. Jousma et al., "EGFR-STAT3 signaling promotes formation of malignant peripheral nerve sheath tumors," Oncogene, vol. 33, no. 2, pp. 173-180, 2014.

[82] C. Gregorian, J. Nakashima, S. M. Dry et al., "PTEN dosage is essential for neurofibroma development and malignant transformation," Proceedings of the National Academy of Sciences of the United States of America, vol. 106, no. 46, pp. 19479-19484, 2009.

[83] V. W. Keng, A. L. Watson, E. P. Rahrmann et al., "Conditional inactivation of Pten with EGFR overexpression in Schwann 
cells models sporadic MPNST,' Sarcoma, vol. 2012, Article ID 620834, 12 pages, 2012.

[84] E. P. Rahrmann, B. S. Moriarity, G. M. Otto et al., "Trp53 haploinsufficiency modifies EGFR-driven peripheral nerve sheath tumorigenesis," American Journal of Pathology, vol. 184, no. 7, pp. 2082-2098, 2014.

[85] S. J. Kazmi, S. J. Byer, J. M. Eckert et al., “Transgenic mice overexpressing neuregulin-1 model neurofibroma-malignant peripheral nerve sheath tumor progression and implicate specific chromosomal copy number variations in tumorigenesis," American Journal of Pathology, vol. 182, no. 3, pp. 646-667, 2013.

[86] R. D. Dodd, J. K. Mito, W. C. Eward et al., "NF1 deletion generates multiple subtypes of soft-tissue sarcoma that respond to mek inhibition," Molecular Cancer Therapeutics, vol. 12, no. 9, pp. 1906-1917, 2013.

[87] A. C. Hirbe, S. Dahiya, D. Friedmann-Morvinski, I. M. Verma, D. Wade Clapp, and D. H. Gutmann, "Spatially- and temporallycontrolled postnatal p53 knockdown cooperates with embryonic Schwann cell precursor Nf1 gene loss to promote malignant peripheral nerve sheath tumor formation," Oncotarget, vol. 7, no. 7, pp. 7403-7414, 2016.

[88] C.-C. H. Stucky, K. N. Johnson, R. J. Gray et al., "Malignant Peripheral Nerve Sheath Tumors (MPNST): The Mayo Clinic experience," Annals of Surgical Oncology, vol. 19, no. 3, pp. 878885, 2012.

[89] W. W. Wong, T. Hirose, B. W. Scheithauer, S. E. Schild, and L. L. Gunderson, "Malignant peripheral nerve sheath tumor: analysis of treatment outcome," International Journal of Radiation Oncology Biology Physics, vol. 42, no. 2, pp. 351-360, 1998.

[90] A. Kaushal and D. Citrin, "The role of radiation therapy in the management of sarcomas," Surgical Clinics of North America, vol. 88, no. 3, pp. 629-646, 2008.

[91] J. C. Yang, A. E. Chang, A. R. Baker et al., "Randomized prospective study of the benefit of adjuvant radiation therapy in the treatment of soft tissue sarcomas of the extremity," Journal of Clinical Oncology, vol. 16, no. 1, pp. 197-203, 1998.

[92] J. Kahn, A. Gillespie, M. Tsokos et al., "Radiation therapy in management of sporadic and neurofibromatosis type 1-associated malignant peripheral nerve sheath tumors," Frontiers in Oncology, vol. 4, article 324, 2014.

[93] A. Ferrari, R. Miceli, A. Rey et al., "Non-metastatic unresected paediatric non-rhabdomyosarcoma soft tissue sarcomas: results of a pooled analysis from United States and European groups," European Journal of Cancer, vol. 47, no. 5, pp. 724-731, 2011.

[94] M. Carli, A. Ferrari, A. Mattke et al., "Pediatric malignant peripheral nerve sheath tumor: the Italian and German soft tissue sarcoma cooperative group," Journal of Clinical Oncology, vol. 23, no. 33, pp. 8422-8430, 2005.

[95] B. C. Widemann, D. K. Reinke, L. J. Helman et al., "SARC006: Phase II trial of chemotherapy in sporadic and neurofibromatosis type 1 (NF1)-associated high-grade malignant peripheral nerve sheath tumors (MPNSTs)," Journal of Clinical Oncology, vol. 31, Article ID 10522, 2013.

[96] K. Albritton, C. Rankin, C. M. Coffin et al., "Phase II trial of erlotinib in metastatic or unresectable malignant peripheral nerve sheath tumor (MPNST)," Journal of Clinical Oncology, vol. 24, Article ID 9518, 2006.

[97] R. G. Maki, D. R. D’Adamo, M. L. Keohan et al., "Phase II study of sorafenib in patients with metastatic or recurrent sarcomas," Journal of Clinical Oncology, vol. 27, no. 19, pp. 3133-3140, 2009.

[98] R. Chugh, J. K. Wathen, R. G. Maki et al., "Phase II multicenter trial of imatinib in 10 histologic subtypes of sarcoma using a bayesian hierarchical statistical model," Journal of Clinical Oncology, vol. 27, no. 19, pp. 3148-3153, 2009.

[99] S. Schuetze, K. Wathen, E. Choy et al., "Results of a Sarcoma Alliance for Research through Collaboration (SARC) phase II trial of dasatinib in previously treated, high-grade, advanced sarcoma," Journal of Clinical Oncology, vol. 28, Article ID 10009, 2010.

[100] M. A. Dickson, M. R. Mahoney, W. D. Tap et al., "Phase II study of MLN8237 (Alisertib) in advanced/metastatic sarcoma," Annals of Oncology, vol. 27, no. 10, pp. 1855-1860, 2016.

[101] A. B. Miller, B. Hoogstraten, M. Staquet, and A. Winkler, "Reporting results of cancer treatment," Cancer, vol. 47, no. 1, pp. 207-214, 1981.

[102] E. A. Eisenhauer, P. Therasse, J. Bogaerts et al., "New response evaluation criteria in solid tumours: revised RECIST guideline (version 1.1)," European Journal of Cancer, vol. 45, no. 2, pp. 228 247, 2009.

[103] H. Choi, C. Charnsangavej, S. C. Faria et al., "Correlation of computed tomography and positron emission tomography in patients with metastatic gastrointestinal stromal tumor treated at a single institution with imatinib mesylate: proposal of new computed tomography response criteria," Journal of Clinical Oncology, vol. 25, no. 13, pp. 1753-1759, 2007.

[104] D. Katz, A. Lazar, and D. Lev, "Malignant peripheral nerve sheath tumour (MPNST): the clinical implications of cellular signalling pathways," Expert Reviews in Molecular Medicine, vol. 11, article e30, 2009. 


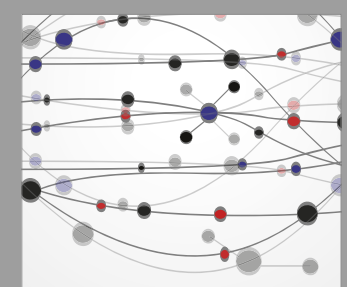

The Scientific World Journal
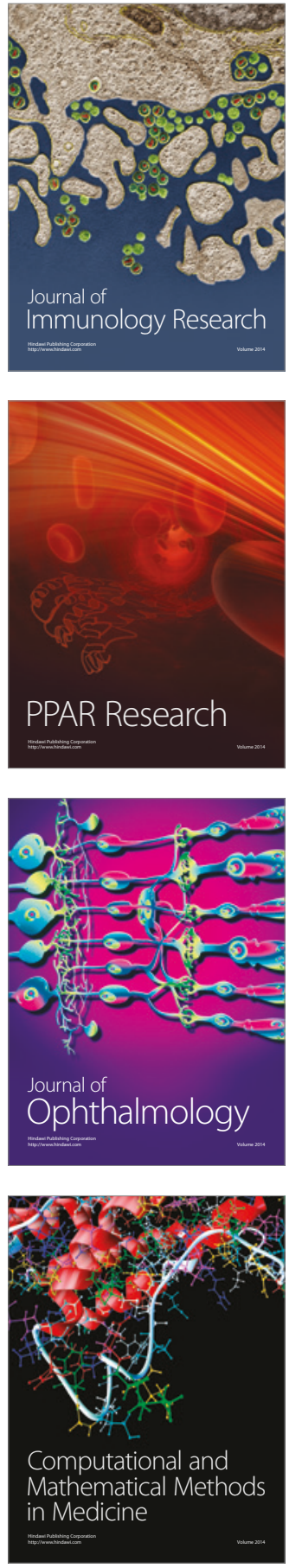

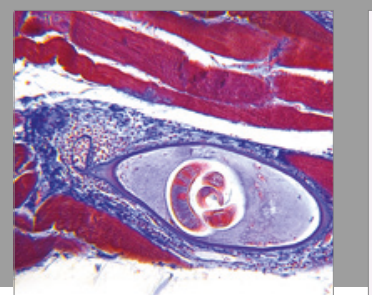

Gastroenterology Research and Practice
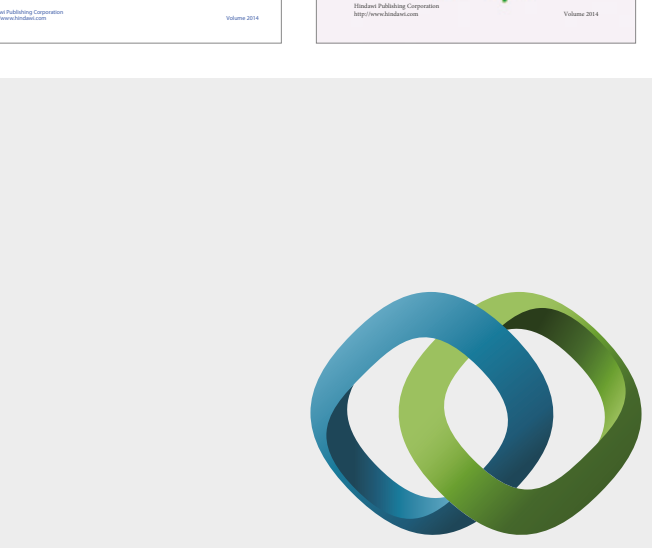

\section{Hindawi}

Submit your manuscripts at

https://www.hindawi.com
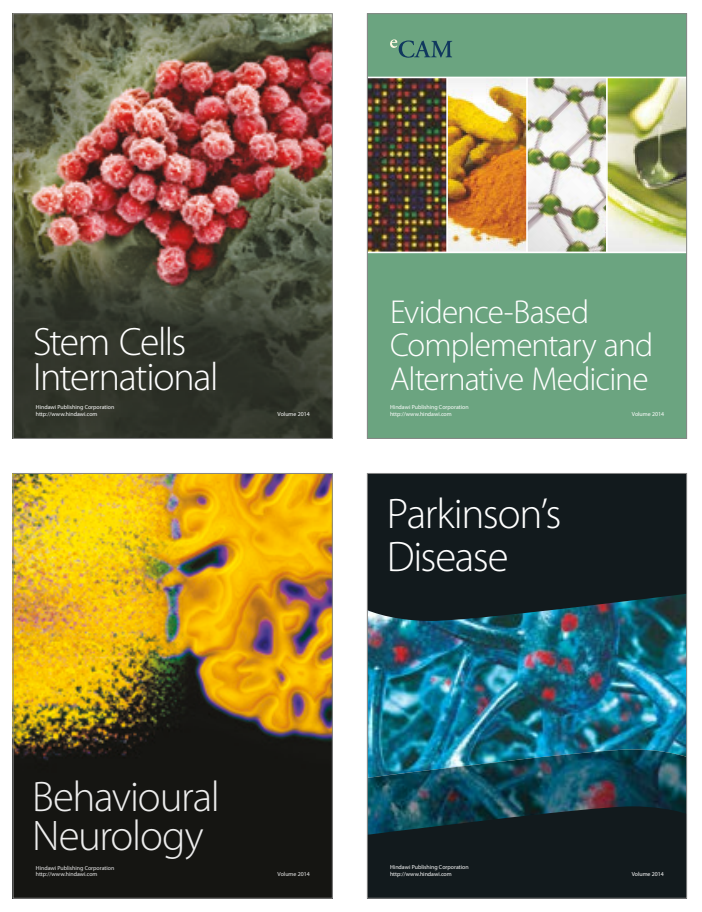
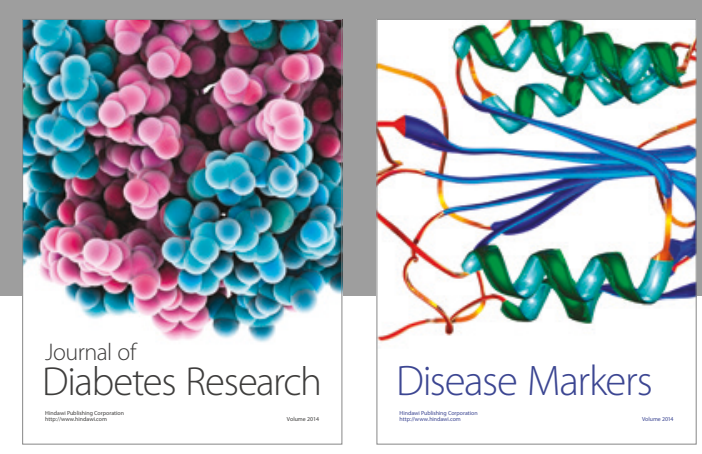

Disease Markers
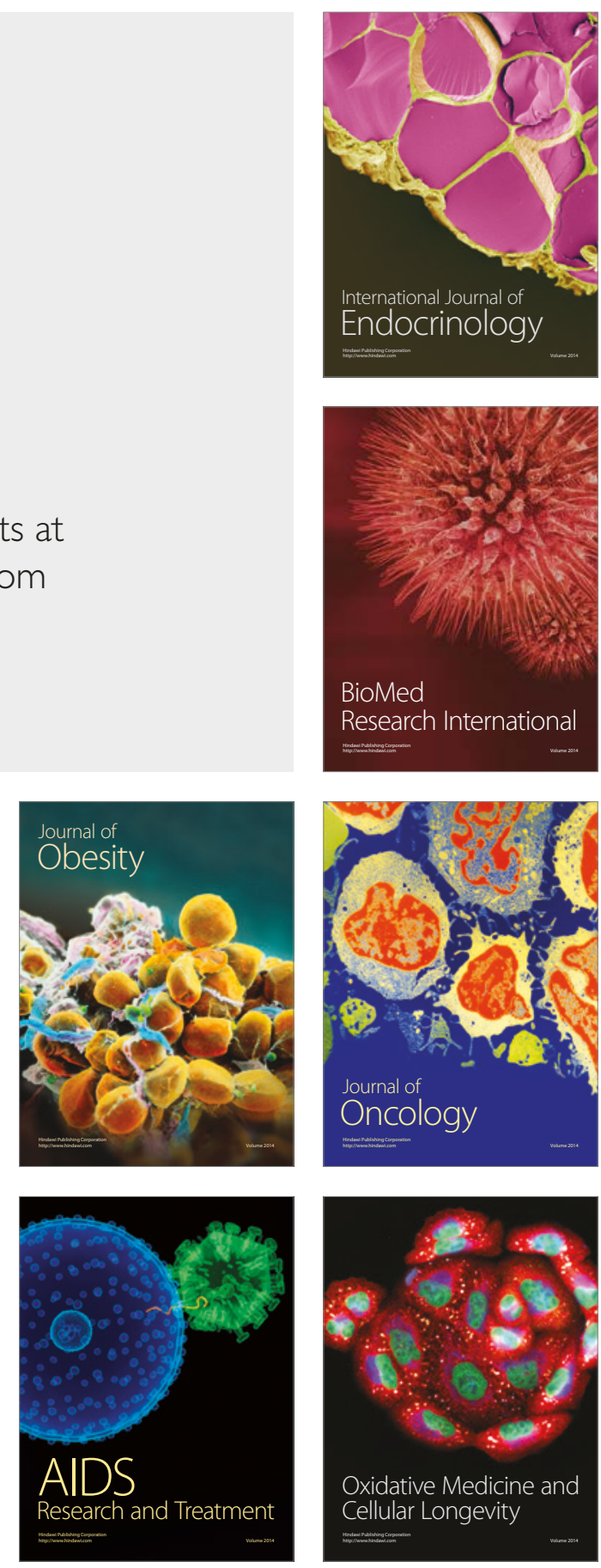